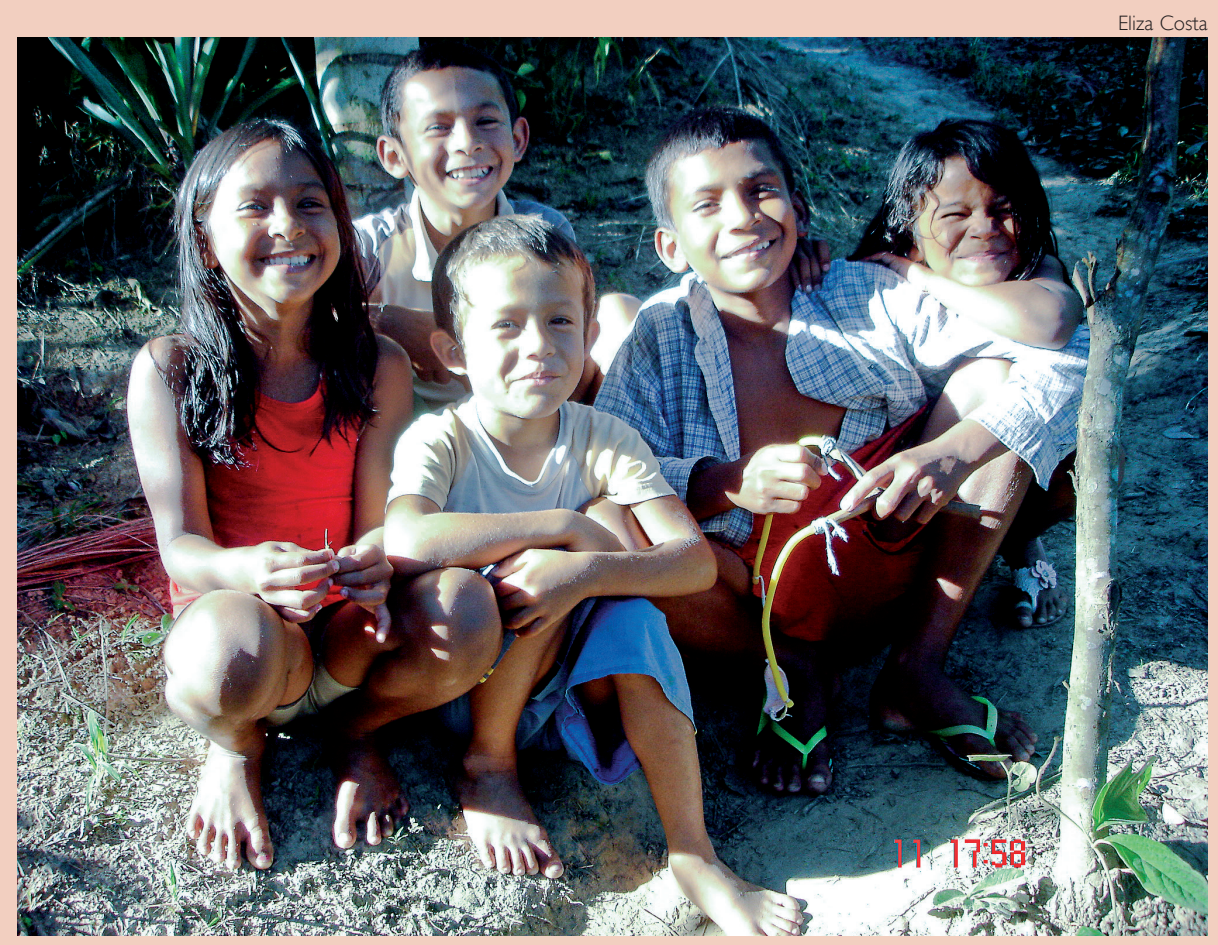

Crianças indígenas moradoras da aldeia Novo Destino, às margens do rio Amônia

AMAZÔNIA

\title{
Identidades móveis revelam a complexidade de direitos indígenas e extrativistas
}

As pessoas, para se socializar, precisam assumir várias facetas de acordo com a situação em que estão. $\mathrm{O}$ que dizer quando esta mudança não ocorre apenas no ambiente superficial dos papéis sociais, mas também se aprofundam e se complexificam a ponto de atingir a identidade de um sujeito?

A cientista social da Universidade Federal do Rio Grande (Furg) Eliza Costa esteve na 36 Reunião da Associação Nacional de Pós-Graduação em Ciências Sociais (Anpocs), em outubro de 2012, para falar de sua pesquisa sobre conflitos entre indígenas e não indígenas na região do rio Amônia (afluente do alto Ju- ruá, no Acre), onde vivem famílias descendentes dos Jaminawa, Ashaninka, Santa Rosa, Konibo, Tchama e Amoaca. A pesquisa explicita o que Eliza resumiu como "um jogo de identidades escolhidas" entre as partes envolvidas. Ela conta que, em 2002, com o crescimento da região, esses descendentes de indígenas decidiram reivindicar direitos a partir da união em torno da identidade Arara, o que culminou em conflitos já que, durante vários anos, eles compartilharam o território com famílias de não índios.

De acordo com a pesquisadora "o conflito tornou-se mais intenso porque, no momento da criação da Terra Indígena Kampa do rio Amônia (na década de 1980) alguns desses mesmos descendentes não quiseram ser identificados como índios, preferindo viver na reserva extrativista ou posteriormente num projeto de assentamento, tal como outras famílias não indígenas. E, hoje essas famílias, apesar do histórico de convivência, poderão ser expulsas, o que tem ocasionado revoltas já que não consideram justo que outros que viveram de forma tão próxima tenham mais direitos que eles". Neste caso, uma das razóes para essa diferenciação, e a aparente diferenciação de direitos, é a própria legislação brasileira. Maria do Rosário Carvalho, antropóloga da Universidade Federal da Bahia (UFBA), lembra que indígenas contam com a Lei 6001/73, que está em vigor e prevê o Estatuto do Índio. "Então, eles partem do pressuposto de que terão benefícios mais assegurados, que saúde e território lhes serão garantidos, mas isso não é um mar de rosas - a exemplo do que está acontecendo com os índios Guarani no Mato Grosso do Sul.

Os antropólogos Augusto Postigo e Roberto Rezende, ambos da Universidade Estadual de Campinas (Unicamp), também estudaram esses conflitos no alto Juruá. Eles ressaltam que o direito à terra, do lado dos indígenas, passava por sua identidade, atestada por laudos antropológicos. Já para os extrativistas, a concessão do direito ao uso do território era feita pelo Ibama, desde que houvesse o comprometimento para a sua preservaçáo. Eles concluem que "enquanto os indígenas ficaram 'protegidos' pelo 
Ministério da Justiça por seu direito originário vinculado a sua identidade étnica, os extrativistas firmaram compromisso com o Ministério do Meio Ambiente de manter uma Unidade de Conservação Nacional", o que os leva os antropólogos a crer que "parece que quem não se identifica como índio e mora na floresta cai na vala comum e nebulosa de pequenos agricultores".

ESCOLHA DE IDENTIDADE A situação em determinados casos é tão crítica que a obtenção de direitos como saúde e educaçáo pode levá-los a escolher a identidade indígena mas depois desistir dela, e tem havido casos assim", conta. Eliza Costa, no entanto, diz que essa questâo sobre identidades não é de forma alguma somente po-

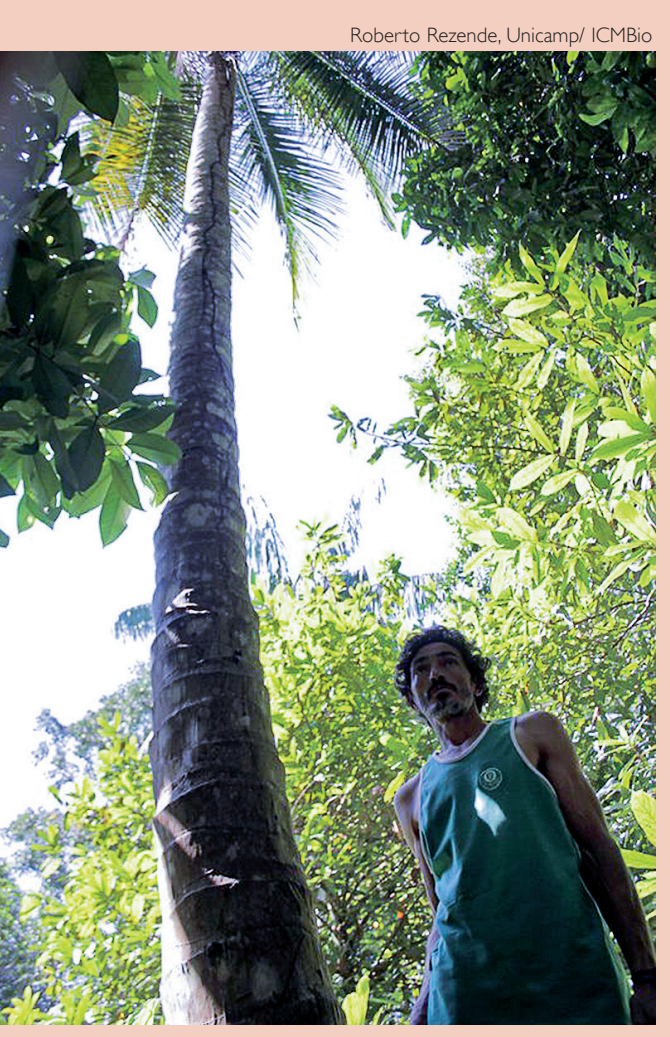

Lió, extrativista não-descendente indígena e coqueiro que plantou há cerca de 25 anos lítica. Maria do Rosário concorda e acrescenta que trata-se de assumir uma identidade que durante anos foi suprimida, em decorrência de uma série de fatos históricos, e isso não tem caráter apenas instrumental, mas "há uma memória de pertencimento étnico indígena, que aflora em certos momentos, por vezes através de uma liderança com mais poder de mobilização e às vezes por causa das ocupaçôes simultâneas", afirma a antropóloga.

O possível choque que a mobilidade identitária pode provocar em não indígenas, mais ainda quando aparenta ser instrumental no sentido do uso político que dela pode ser feito na demarcação de territórios, vem em parte da imagem de "bom selvagem", puro e inocente, que brasileiros não indígenas criam acerca dos índios, que substitui a imagem do indígena real - o que Alcida Ramos, antropóloga da Universidade de Brasília (UnB), considera como o "índio hiper-real", já que a imagem que dele se projeta é "mais real" que a realidade. E isso tem um papel muito importante na delimitação dessas identidades: como conclui Maria do Rosário, "o Estado ainda parece precisar de uma imagem 'pura' ou hiper-real do que considera 'ser indígena' para elaborar suas políticas enquanto a realidade ébastante mais complexa do que isto" - e, a exemplo dos recentes conflitos que vêm ocorrendo no Mato Grosso do Sul (referente ao pedido de reconhecimento das terras por parte dos índios Guarani-Kaiowá), é uma questão longe de uma solução.

Meghie Rodrigues

\section{RESENHA}

A trajetória etno-histórica
de uma população indígena

Os Camba-Chiquitano tiveram sua identidade e história revelada e analisada pelo historiador Giovani José da Silva em seu livro Identidades cambiantes: os Kamba na fronteira Brasil-Bolívia (editora UFG), lançado em novembro passado. A obra, uma adaptação do doutorado defendido em 2009 pela mesma universidade, traz uma análise sobre o desenvolvimento etno-histórico das identidades de uma comunidade indígena localizada atualmente em Corumbá (MS). 0 autor procurou, através de fontes orais, resgatar a história das identidades assumidas pelos ancestrais Kamba, os Chiquitanos, por meio de fontes orais. Uma parcela desses indígenas viveu na fronteira Brasil-Bolívia durante a segunda metade do século $X X$. A diáspora dos ancestrais está intimamente ligada a mudanças dos espaços sociais urbanos que pressionaram aqueles que rejeitaram se submeter à servidão ou à "economia de contrabando" a buscar novas áreas. 0 autor se debruça sobre a percepção e o entendimento de como essa comunidade elaborou identidades e práticas culturais para viver e quais estratégias adotou para que Ihe fosse garantida a sobrevivência física e cultural em uma região transnacional. Os CambaChiquitanos reconhecem sua própria alteridade e diferença, agregando valores positivos a estigmas que recaíram sobre o grupo. 